\title{
SECONDARY STRUCTURE OF BARLEY SERINE PROTEINASE INHIBITOR 2 DETERMINED BY PROTON NUCLEAR MAGNETIC RESONANCE SPECTROSCOPY
}

\author{
by \\ MOGENS KJ/ER and FLEMMING M. POULSEN \\ Department of Chemistry, Carlsberg Laboratory, \\ Gamle Carlsberg Vej 10, DK-2500 Copenhagen Valby, Denmark
}

Keywords: $\alpha$-helix, $\beta$-structure, reverse turn, NOE, NMR

\begin{abstract}
The secondary structure of BSPI- 2 has been determined using information obtained exclusively from ${ }^{1} \mathrm{H}-\mathrm{NMR}$ recordings of Nuclear Overhauser effects, coupling constants and hydrogen exchange rates. It is shown that the protein contains one $\alpha$-helix and a six-stranded $\beta$-sheet. Four of the strands form an anti-parallel $\beta$-sheet, and two form a parallel. In addition, six turns and one half turn have been identified. The segment containing the active site shows no secondary structure. This secondary structure is in close agreement with the structure determined by X-ray crystallography (C.A. MCPHALEN and M.N.G. JAMES, Biochemistry 26, 261-269 (1987)) and from NMR by means of distance geometry followed by restrained molecular dynamics based on the total number of NOE effects (G.M. Clore, A.M. Gronenborn, M. KJeR and F.M. Poulsen, Protein Engineering 1, 305-311 (1987)).
\end{abstract}

\section{INTRODUCTION}

In the preceeding paper (6) the sequence specific assignment of the proton NMR spectrum of BSPI-2 was described. In the present report we are concerned with the identification of secondary structure components such as $\alpha$ helices, parallel and anti-parallel $\beta$-sheets and reverse turns, based on measurements of sequential and long-range nuclear Overhauser effects between backbone protons, ${ }^{3} \mathrm{~J}_{\mathrm{H}^{\mathrm{N}} \mathrm{H}^{\alpha}}$ coupling constants and amide hydrogen exchange kinetics. It is well established $(13,14)$ that each of the secondary structure types is characterized by a typical pattern of these NMR parameters, which allow unambiguous determination of the secondary structure of a particular peptide segment, and the method has been successfully applied to several other proteins $(1,2,3,7,10$, $12,15,16)$.

\section{MATERIALS AND METHODS}

The description of NMR experiments, the data processing, the equipment and the materials used were as described in the preceeding paper (6). ${ }^{3} \mathrm{~J}_{\mathrm{H}^{\mathrm{N}} \mathrm{H}^{\mathrm{a}}}$ coupling constants were obtained from the two-dimensional COSY spectra, and measured in the $\omega_{2}$ axis from the $\mathrm{H}^{\mathrm{N}}-\mathrm{H}^{\alpha}$

Abbreviations: BSPI-2 = Barley Serine Proteinase inhibitor 2; (19-83)BSPI-2 = the C-terminal part of BSPI-2 starting at residue 19 and ending at residue 83; $\operatorname{COSY}=$ Two-Dimensional Correlation Spectroscopy; NMR = Nuclear Magnetic Resonance; NOESY = Two-dimensional Nuclear Overhauser Spectroscopy; NOE = Nuclear Overhauser effect; $\mathrm{ppm}=$ parts per million. The nomenclature for the atoms of the amino acid was according to the IUPAC-IUB recommendation. (IUPAC-IUB Commision of Biochemical Nomenclature 1969. Biochemistry 9, 3471-3479 (1970)). 
M. KJER \& F.M. POULSEN: Secondary structure of BSPI-2 by 'H-NMR

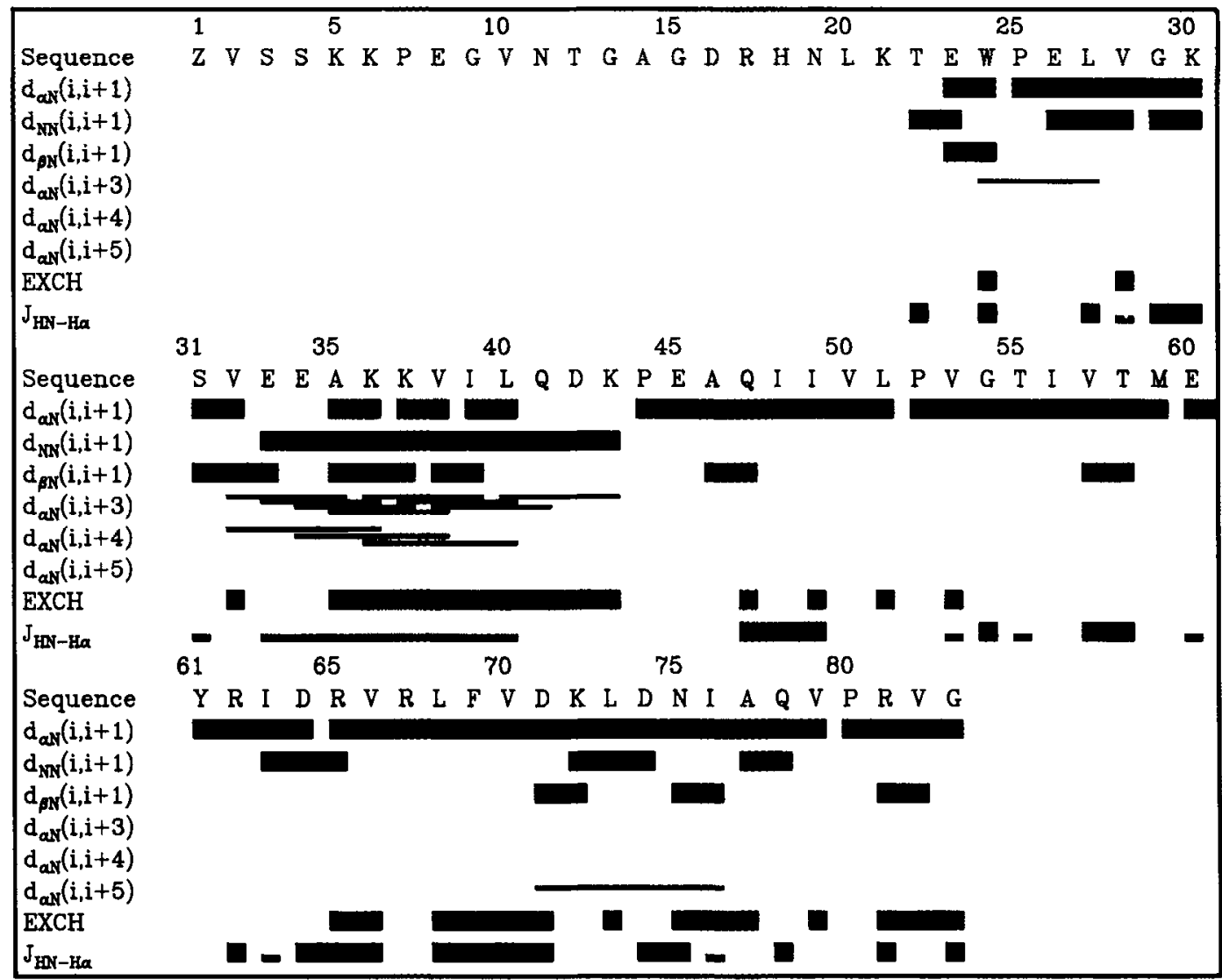

Figure 1. Summary of sequential NOE's, ${ }^{3} \mathrm{~J}_{\mathrm{H}^{N} \mathrm{H}^{\alpha}}$ coupling constants and amide hydrogen exchange in (19-83) BSPI-2.

A mark in the $\mathrm{EXCH}$ line indicates that the amide proton exchanges slowly. A thin bar in the coupling constant line indicates that the coupling constant is less than $7 \mathrm{~Hz}$, a thick bar that it is greater than $8 \mathrm{~Hz}$.

cross peaks. Amide hydrogen exchange with deuterium was measured by recording the intensities of the $\mathrm{H}^{\mathrm{N}}-\mathrm{H}^{\mathrm{a}}$ cross peaks in COSY spectra of the protein dissolved in $99.9 \%$ deuterium oxide. The intensities of individual peaks were compared with the intensities of the respective cross peaks in spectra recorded of the protein in a $90 \% / 10 \% \mathrm{H}_{2} \mathrm{O} / \mathrm{D}_{2} \mathrm{O}$ mixture.

\section{RESULTS}

On the basis of the patterns of sequential NOE's found throughout the sequence of the (19-83)BSPI-2, Figure 1, and additional information obtained from long distance peptide backbone NOE's, measurements of the ${ }^{3} \mathrm{~J}_{\mathrm{H}^{N} \mathrm{H}^{\mathrm{a}}}$ coupling constants and hydrogen exchange of the amide hydrogens of the peptide backbone, Figure 1, the secondary structure was determined using the rules described by WAGNER et al. (13).

This analysis showed that the peptide chain forms three distinct compartments of secondary structures: one $\alpha$-helix, a $\beta$-sheet region composed of six short strands of anti-parallel $\beta$-sheet and two longer strands of parallel $\beta$-sheet and a loop. A schematic presentation of the secondary structure of BSPI-2 is shown in Figure 2.

\subsection{The $a$-helix(32-43)}

The $a$-helix starts at residue Val-32 and is 


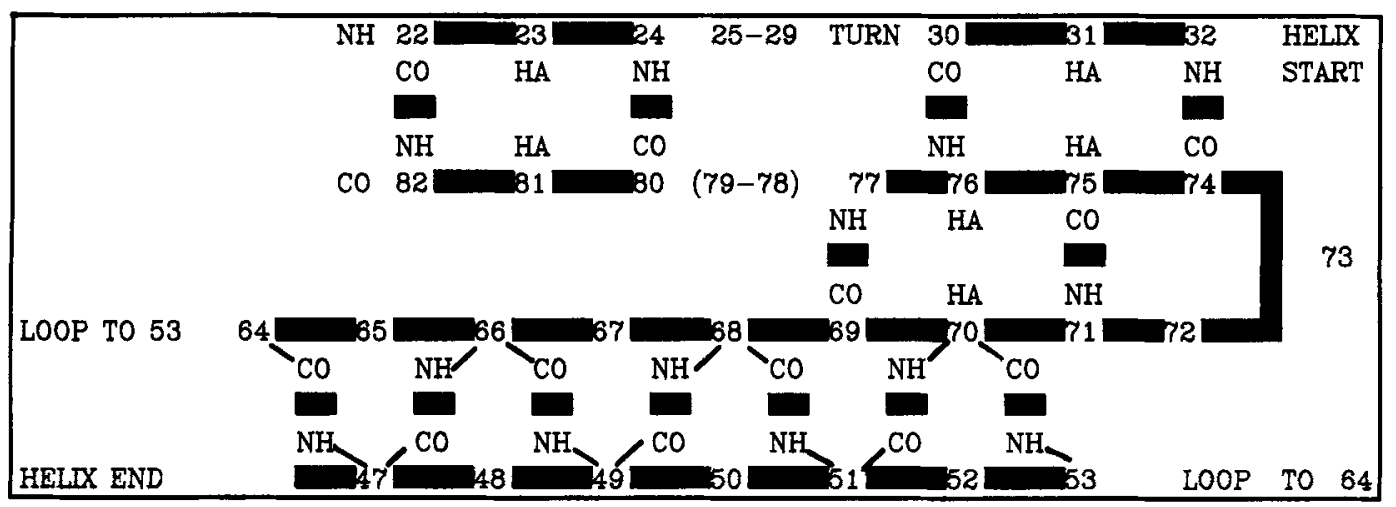

Figure 2. Schematic presentation of the secondary structure of (19-83)BSPI-2. Hydrogen bonds are marked with an interstrand bar.

terminated after Lys-43 at Pro-44. The evidence for the presence of this helix is summarized in Figure 1. The typical NOE's expected in $\alpha$-helices are found in this part of the sequence. These are $d_{N N}(i, i+1), d_{a N}(i, i+3)$ and $d_{a N}(i, i+4)$ effects. In addition, the small ${ }^{3} \mathrm{~J}_{\mathrm{H}^{N} \mathrm{H}^{\alpha}}$ coupling constant as well as slow amide hydrogen exchange for the peptide hydrogens in the central part of the helix provide sufficient evidence for the presence of an $\alpha$-helix in this region of the amino acid sequence.

\subsection{The $\beta$-sheet}

The $\beta$-sheet comprises 6 strands as shown in
Figure 2. These are I: 22-24; II: 30-32; III: 47-53; IV: 64-71; V: 74-76 and VI: 80-82. Strands I and VI, II and V, and the C-terminal part of IV (69-71) and $V$ each form the three short segments of anti-parallel $\beta$-sheet. Strands III and IV form the parallel $\beta$-sheet.

\subsubsection{The anti-parallel $\beta$-strands}

The following criteria, were used to identify the peptide segments in the polypeptide chain which are part of anti-parallel $\beta$-sheet structures. Firstly, the coupling constant is normally larger than $7 \mathrm{~Hz}$, secondly strong NOE's between $\mathrm{H}^{0}$

Table I. Inter-strand long range NOE's in anti-parallel $\beta$-sheets in (19-83)BSPI-2.

\begin{tabular}{lllc}
\hline $\mathrm{H}^{\mathrm{a}}-\mathrm{H}^{\mathrm{a}}$ & \multicolumn{2}{l}{ chemical shifts* } & strand \\
\hline Glu-23 to Arg-81 & 5.34 & 5.72 & I to VI \\
Ser-31 to Asn-75 & 5.00 & 5.40 & II to V \\
Val-70 to Ile-76 & 5.35 & 4.05 & IV to V \\
& & & \\
$\mathrm{H}^{\mathrm{a}}-\mathrm{H}^{\mathrm{N}}$ 's & & & \\
Glu-23 to Val-82 & 5.34 & 8.48 & I to VI \\
Arg-81 to Trp-24 & 5.72 & 8.25 & III to I \\
Ser-31 to Ile-76 & 5.00 & 9.09 & II to V \\
Asn-75 to Val-32 & 5.40 & 8.35 & V to II \\
Val-70 to Ala-77 & 5.35 & 9.50 & IV to V \\
lle-76 to Asp-71 & 4.05 & 8.79 & V to IV \\
\hline
\end{tabular}

" Chemical shifts recorded at $\mathrm{pH} 4.2$ and $42^{\circ} \mathrm{C}$ and values are given in ppm relative to the methyl group proton resonances of 4,4-dimenthyl-4-silapentane. 


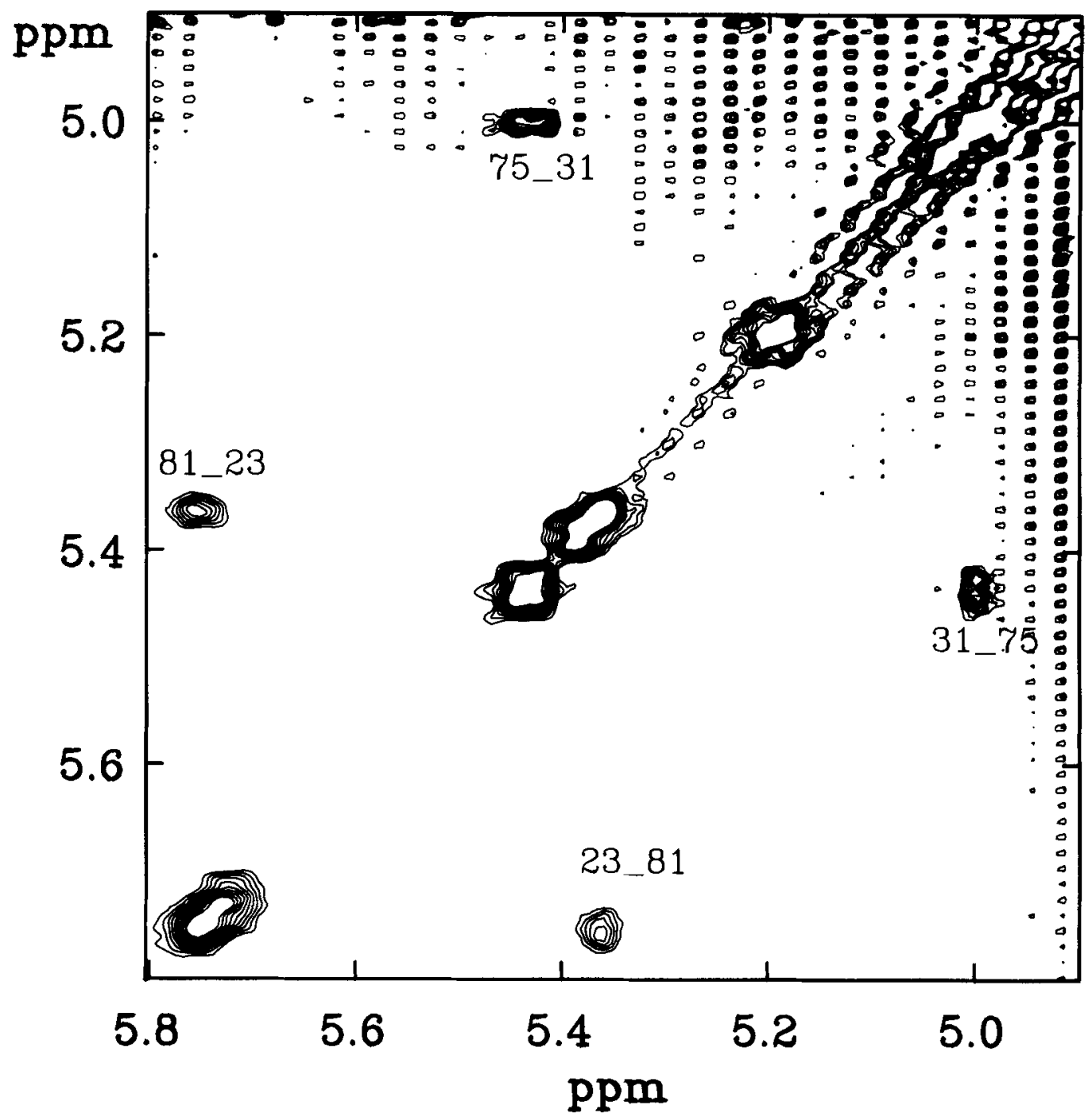

Figure 3. NOESY spectrum of (19-83)BSPI-2 (0.01 M, pH 4.2, $99.96{ }^{2} \mathrm{H}_{2} \mathrm{O}, 22{ }^{\circ} \mathrm{C}$ mixing time $0.20 \mathrm{~s}$ ) showing the $\mathrm{H}^{\alpha}$ - $\mathrm{H}^{\mathrm{a}}$ NOE's of the anti-parallel $\beta$-strands. The labelling of the peaks refers to the sequence number of the respective residues whose $\mathrm{H}^{\alpha}$ are involved.

protons in the two oppositely directed peptide segments could be found, thirdly, NOE's between $\mathrm{H}^{\mathrm{N}}$ and $\mathrm{H}^{\alpha}$ protons across the two peptide strands are normally observed, fourthly, NOESY cross peaks of the type $d_{a N}(i, i+1)$ are normally strong in the individual strands, and finally, it is sometimes observed that the amide exchange rates along the peptide chain alternate between slow and fast in each of the anti-parallel strands reflecting that every second amide hydrogen is involved in hydrogen bonds, unless the strand is interior in $\beta$-structures, with more than two strands. By using these criteria, three short strands of anti-parallel $\beta$-sheet structures were found. The evidence for the existence of these structures is summarized in Table I. Firstly, there are for each of the three pairs of anti-parallel $\beta$-structures one strong cross strand $\mathrm{H}^{\mathrm{a}}-\mathrm{H}^{\mathrm{a}}$ NOE namely those of residues $23,81,31,75$ and 70,76 . Two of these three NOE's are shown in Figure 3. Secondly, each of the six $\mathrm{H}^{\mathrm{a}}$ have weak or intermediate NOE's to the $\mathrm{H}^{\mathrm{N}}$ of the amino 
acid neighbour one position forward of the $\mathrm{H}^{\mathrm{a}}$ on the opposite strand to which the interchain $d_{\alpha u}$ NOE were observed. In Table I are listed the chemical shift positions of each of the NOE's which give evidence for the anti-parallel $\beta$-structures in the BSPI-2. Further support for this is the observation that each of the hydrogen bond forming amide hydrogens are in the slow exchange category, see Figure 1. As far as the ${ }^{3} \mathrm{~J}_{\mathrm{H}^{N} \mathrm{H}^{\mathrm{u}}}$ coupling constants are concerned all except two fall in the category larger than $7 \mathrm{~Hz}$. The two exceptions are Val-32 and Ile-76.

\subsubsection{The parallel $\beta$-strands}

The criteria for identification of strands of parallel $\beta$-structure are in principle the same as those used for anti-parallel $\beta$-strands except that the strong $\mathrm{H}^{\alpha}-\mathrm{H}^{\alpha}$ cross strand NOE is missing in these structures. The predominant sequential NOE's are the $d_{\alpha N}(i, i+1)$. The coupling constants as for the anti-parallel strands are expected to be larger than $7 \mathrm{~Hz}$. Also the alternating slow and fast exchanging amides should be found along the peptide chain, except in those strands sandwiched between two other strands. Hence, the characteristica which allow distinction between the two types of $\beta$-structures are firstly that the interstrand $\mathrm{H}^{\alpha}-\mathrm{H}^{\alpha}$ NOE's are not expected in the parallel $\beta$-structure and the positive identification of the anti-parallel $\beta$ structure is the presence of weak NOE's of the $d_{\mathrm{aN}}$-type which alternate along the strands so that the $\mathrm{H}^{\mathrm{N}}$ in position $\mathrm{i}$ in one of the strands $(\mathrm{A})$ has an NOE to the $\mathrm{H}^{\alpha}$ in position $\mathbf{j}$, in the other strand $(B)$, the $\mathrm{H}^{\alpha}$ in position $\mathbf{i}+\mathbf{l}$ (strand $\mathrm{A}$ ) has an $N O E$ to the $H^{\mathrm{N}}$ in position $\mathbf{j}+\mathbf{1}$ (strand $\mathrm{B}$ ) and so on. The weak NOE's listed in Table II show clearly that the peptide segment 47 through 53 and 64 through 70 form a parallel $\beta$-structure. Further evidence for this is the observation that each of the six $\mathrm{H}^{\mathrm{N}}$ 's which have NOE's to $\mathrm{H}^{\mathrm{a}}$ on the other strand are slowly exchanging in agreement with the expected hydrogen bond formation to carbonyls on the other strand.

\subsection{Reverse turns}

The criteria for reverse turns of type I, II and III and their mirror images have been outlined
Table II. Long range weak $\mathbf{H}^{N}-H^{a}$ and $\mathbf{H}^{N}-H^{N}$ NOE's in the parallel $\beta$-sheet.

\begin{tabular}{lll}
\hline $\mathrm{H}^{\mathrm{a}}-\mathrm{H}^{\mathrm{N}}$ & \multicolumn{2}{c}{ chemical shift* } \\
\hline Arg-65 to Glu-47 & 5.20 & 8.87 \\
Ile-48 to Val-66 & 4.78 & 8.22 \\
Arg-67 to Ile-49 & 4.68 & 7.94 \\
Val-50 to Leu-68 & 4.71 & 9.06 \\
Phe-69 to Leu-51 & 5.71 & 9.09 \\
Pro-52 to Val-70 & 4.83 & 8.75 \\
& & \\
$\mathrm{H}^{\mathrm{N}}$-H & \\
Leu-51 to Val-70 & 9.09 \\
\hline * Chemical shifts at pH 4.2 and $42{ }^{\circ} \mathrm{C}$ and values are \\
given in ppm relative to the methyl group proton \\
resonances of 4,4-dimenthyl-4-silapentane.
\end{tabular}

by WAGNER et al. (13). In the present study, a number of reverse turns which connect the individual segments of secondary structure has been observed. Between segment I and II three overlapping turns were identified using only NMR evidence as described by WAGNER et al. (13). These are two type I turns formed by Trp-24-Leu-27 and Pro-25-Val-29 and type II turn of Leu-27-Lys-30: The $\alpha$-helix and segment III are connected by a type I turn of residues Pro-44-Glu-47. The end of the loop-region and segment IV are connected by a type I turn Arg-62 to Arg-65 and so is the C-terminal part of segment IV and segment $\mathrm{V}$ by the backbone of residues Asp-71 and Asp-74. Segment V and VI are connected by a so-called "half turn" of residues Ala-77 and Val-79.

\subsection{The loop-region}

The peptide segment of residues Gly-54 to Ile- 63 shows no characteristica of any type of secondary structure. All the $\mathrm{H}^{\mathrm{N}}$ 's of this peptide segment exchange fast and were never observed in recordings of the spectrum in deuterium oxide. This region of the protein contains the active site (11) and is referred to as "the loop" because the peptide segment apparently forms an extended structure connecting the two strands (III and IV) of the parallel $\beta$-sheet. 
Table III. Hydrogen Bonds in (19-83) as suggested by the secondary structure determination.

\begin{tabular}{|c|c|c|c|}
\hline \multirow{2}{*}{$\begin{array}{l}\mathrm{H}^{\mathrm{N}}-\mathrm{CO} \\
\text { Trp-24 to Pro- } 80\end{array}$} & \multirow{2}{*}{$\begin{array}{c}\begin{array}{c}\text { Amide exchange } \\
\text { of } \mathrm{H}^{\mathrm{N}}\end{array} \\
\text { slow }\end{array}$} & \multicolumn{2}{|c|}{ Secondary structure } \\
\hline & & Strand I to VI & anti-parallel $\beta$ \\
\hline Leu-27 to Trp-24 & fast & & turn I \\
\hline Gly-29 to Pro- 25 & fast & & turn I \\
\hline Lys-30 to Leu-27 & slow & & turn II \\
\hline Val-32 to Asp-74 & slow & Strand II to $\mathrm{V}$ & anti-parallel $\beta$ \\
\hline Ala-35 to Ser-31 & slow & & $\alpha$-helix \\
\hline Lys-36 to Val-32 & slow & & $\alpha$-helix \\
\hline Lys-37 to Glu-33 & slow & & $\alpha$-helix \\
\hline Val-38 to Glu-34 & slow & & $a$-helix \\
\hline Ile-39 to Ala-35 & slow & & $\alpha$-helix \\
\hline Leu-40 to Lys 36 & slow & & $\alpha$-helix \\
\hline Glu-41 to Lys-37 & slow & & $\alpha$-helix \\
\hline Asp-42 to Val-38 & slow & & $\alpha$-helix \\
\hline Lys-43 to Ile-39 & slow & & $\alpha$-helix \\
\hline Glu-47 to Pro-44 & slow & & turn I \\
\hline Glu-47 to Asp-64 & slow & Strand III to IV & parallel $\beta$ \\
\hline Ile-49 to Val-66 & slow & Strand III to IV & parallel $\beta$ \\
\hline Leu-51 to Leu-68 & slow & Strand III to IV & parallel $\beta$ \\
\hline Val-53 to Val-70 & slow & Strand III to IV & parallel $\beta$ \\
\hline Arg- -65 to Arg-62 & slow & & turn I \\
\hline Val-66 to Glu-47 & slow & Strand IV to III & parallel $\beta$ \\
\hline Leu-68 to Ile-49 & slow & Strand IV to III & parallel $\beta$ \\
\hline Val-70 to Leu-51 & slow & Strand IV to III & parallel $\beta$ \\
\hline Asp-74 to Asp-71 & fast & & turn I \\
\hline Asp-71 to Asn-75 & slow & Strand IV to V & anti-parallel $\beta$ \\
\hline Ile-76 to Lys-30 & slow & Strand V to II & anti-parallel $\beta$ \\
\hline Ala-77 to Phe-69 & slow & Strand $\mathrm{V}$ to IV & anti-parallel $\beta$ \\
\hline Val-82 to Thr-22 & slow & Strand VI to I & anti-parallel $\beta$ \\
\hline
\end{tabular}

1) Measured at $\mathrm{pH} 4.2$ and $22^{\circ} \mathrm{C}$. Exchange of an amide hydrogen was considered fast if the $\mathrm{H}^{\alpha}-\mathrm{H}^{\mathrm{N}}$ cross peak was absent in the COSY spectrum immediately after dissolution of the protein, and otherwise slow.

\subsection{Hydrogen bonds}

In outlining the secondary structure of BSPI-2 using the compiled NMR information the possible existence of the hydrogen bonds in the peptide backbone of the structure can be predicted. The secondary structure as determined in the previous sections suggests the presence of 28 hydrogen bonds. The amide hydrogens involved and their likely carbonyl partners in the hydrogen bonds are listed in Table III. The listing includes 25 slowly exchanging amide hydrogens and it is characteristic that the remaining three are all proposed to be in reverse turns which are known to exist preferentially on the surface of proteins where amide exchange is normally fast.

\section{DISCUSSION}

The present work has outlined the secondary structure of (19-83)BSPI-2 using exclusively information obtained from NMR observations. The three-dimensional structure of the protein has previously been determined by $\mathrm{X}$-ray crystallography $(8,9)$, and it is clearly interesting to compare the results obtained by these two inde- 
pendent methods. In virtually all respects the two methods have come to the same result. The secondary structures determined by X-ray crystallography and by NMR spectroscopy are almost in complete agreement. All of the secondary structure elements that were indicated by the NMR-data are seen in the X-ray structure and the hydrogen bonds proposed in this work are plausible from the $\mathrm{X}$-ray coordinates of the relevant nitrogen and oxygen positions. In our NMR studies of the BSPI-2 we have determined the three-dimensional structure using a combination of distance geometry and restrained molecular dynamics $(4,5)$. This structure also confirms the secondary structure elements outlined in the present study.

\section{ACKNOWLEDGEMENTS}

We thank Professor MARTIN OTTESEN for critical reading of this manuscript. The BRUKER AM 500 MHZ NMR spectrometer was provided by the Danish Natural Science Recearch Council and the Carlsberg Foundation of Copenhagen. We thank the Institute of Organic Chemistry, The Technical University of Denmark for housing the spectrometer and we thank Dr. KLAUS BOCK for help and advice, Dr. I. SvENDSEN for performing $\mathrm{N}$-terminal analysis of (19-83)BSPI2 and checking the purity of the N-terminal blocked BSPI-2. We also thank JeTTE HolsøE and ANNETTE PETTERSSON for assistance in preparing the manuscript and PIA MIKKELSEN for skilled technical assistance in preparing both (19-83)BSPI-2 and the BSPI-2. We thank Dr. I. JONASSEN for providing the first samples of BSPI-2.

\section{REFERENCES}

1. ARseniev. A. S. V. I. Kondakov, V. N. MaIorov \& F. BYSTROV: NMR solution spatial structure of 'short' scorpion insectotoxin $\mathrm{I}_{5} \mathrm{~A}$. FEBS Lett. 165, $57-62(1984)$

2. Braun, W., G. Wagner, E. Wörgötter, M. VÂSÁK, J. H. R. KÄGI\& K. WÜTHRICH: Polypeptide fold in the two metal clusters of metallo-thionein-2 by nuclear magnetic resonance in solution. J. Mol. Biol. 187, 125-129 (1986)
3. Carver, J. A.. R. M. Cooke, G. Esposito, I. D. CAMPBELL, H. Gregory \& B. SHEARD: A high resolution 'H NMR study of the solution structure of human epidermal growth factor. FEBS Lett. 205, 77-81 (1986)

4. Clore.G.M.. A. M. Gronendorn, M. Kuer \& F. M. POULSEN: The determination of the three-dimensional structure of barley serine proteinase inhibitor 2 by nuclear magnetic resonance spectroscopy, distance geometry and restrained molecular dynamics. Protein Engineering 1, 305-311 (1987)

5. Clore. G. M., A. M. Gronenborn, M. N. G. James, M. KJAR, C. A. MCPHALEN \& F. M. POUlsen: Comparison of the solution and X-ray structure of barley serine proteinase inhibitor 2 . Protein Engineering 1, 313-318 (1987)

6. KJÆR. M., S. Ludvigsen, O. W. Sørensen, L. A. DenYs, J. Kindtler \& F. M. Poulsen: Sequence specific assignment of the proton nuclear magnetic resonance spectrum of barley serine proteinase inhibitor 2. Carlsberg Res. Commun. 52, 327-354 (1987)

7. Klevit, R. E., G. P. Drobny \& E. B. Waygood: Two-dimensional ' $H$ NMR studies of histidinecontaining protein from Escherichia coli 1 . Sequential resonance assignments. Biochemistry 25 , 7760-7769 (1986)

8. McPhalen, C. A., I. Svendsen, I. Jonassen \& M. N. G. JAMES: Crystal and molecular structure of chymotrypsin inhibitor 2 from barley seeds in complex with subtilisin Novo. Proc. Natl. Acad. Sci. USA 82, 7242-7246 (1986)

9. MCPhalen, C. A.\& M. N. G. James: Crystal and molecular structure of the serine proteinase inhibitor Cl-2 from barley seeds. Biochemistry 26 , 261-269 (1987)

10. Sukumaran, D. K., G. M. Clore, A. Preuss, J. Zarbock \& A. M. Gronenborn: Proton nuclear magnetic resonance of hirudin: Resonance assignment and secondary structure. Biochemistry 26 , 333-338 (1987)

11. SVENDSEN I. \& I. JONASSEN: Identification of the reactive sites in two homologous serine proteinase inhibitor isolated from barley. Carlsberg Res. Commun. 47, 199-203 (1982)

12. Ven. F. J. M VAN DE \& C. W. Hilbers: Sequential resonance assignments as a basis for the determination of a three-dimensional structure of protein E-L30 of Escherichia coli. J. Mol. Biol. 192, 419-441 (1986)

13. Wagner, G., D. Neuhaus, E. Worgotter, M. VASÁK, J. R. H. KÄGI \& K. WÜTHRICH: Nuclear magnetic resonance identification of "half-turn" and $3_{10}$-helix secondary structure in rabbit liver 
metallothionein 2. J. Mol. Biol. 187, 131-135 (1986)

14. WUTHRICH, K.: NMR of Proteins and Nuclear Acids. (John Wiley \& Sons) (1986)

15. ZARbock, J., G. M. Clore \& A. M. Gronenborn: Nuclear magnetic resonance study of the globular domain of chicken histone H5: Resonance assignment and secondary structure. Proc. Natl. Acad.
Sci. USA 83, 7628-7632 (1986)

16. ZUIDERWEG, E. R. P., R. KAPTEIN \& K. WÜTHRICH: Sequence-specific resonance assignments in the ${ }^{1} \mathrm{H}$ nuclear-magnetic-resonance spectrum of the lac repressor DNA-binding domain 1-51 from Escherichia coli by two-dimensional spectroscopy. Eur. J. Biochem. 137, 279-292 (1983)

Accepted by H. KLENOW 